\title{
Methylation status of DJ-1 in leukocyte DNA of Parkinson's disease patients
}

\author{
Yuyan $\operatorname{Tan}^{1+}$, Li Wu ${ }^{2+}$, Dunhui Li ${ }^{1}$, Xiaoli Liu', Jianqing Ding ${ }^{1}$ and Shengdi Chen ${ }^{1,3^{*}}$
}

\begin{abstract}
Background: DJ-1 has been thought as a candidate biomarker for Parkinson's disease (PD). It was found reduced in PD brains, CSF and saliva, although there were conflicting results. How DJ-1 expression may be regulated is not clear. Recently, blood-based DNA methylation represents a highly promising biomarker for PD by regulating the causative gene expression. Thus, in this study, we try to explore whether blood-based DNA methylation of DJ-1 could be used as a biomarker to differentiate PD patients from normal control (NC), and whether DNA methylation could regulate DJ-1 expression in a SH-SY5Y cell model.

Methods: Forty PD patients and 40 NC were recruited in this study. DNA was extracted from peripheral blood leukocytes (PBLs). Methylation status of two CpG islands (CpG1 and CpG2) in promoter region of DJ-1 was explored by bisulfite specific PCR-based sequencing method. Methylation inhibitor 5-Aza-dC was used to treat SH-SY5Y cell line, DJ-1 level was detected in both mRNA and protein level.

Results: $\mathrm{CpG}$ sites in these two CpG islands (CpG1 and CpG2) of DJ-1 were unmethylated in both PD and NC group. In SH-SY5Y cell model treated by methylation inhibitor, there was no significant change of DJ-1 expression in either mRNA level or protein level.

Conclusions: Our results indicated that DNA methylation inhibitor didn't alter DJ-1 gene expression in SH-SY5Y cell model, and DNA methylation of DJ-1 promoter region in PBLs level might not be an efficient biomarker for PD patients.
\end{abstract}

Keywords: Parkinson's disease, DJ-1, DNA methylation, Peripheral blood leukocytes

\section{Background}

Parkinson's disease (PD) is the second most common neurodegenerative disorders, pathologically characterized by a progressive degeneration of dopaminergic neurons and the presence of intracytoplasmic Lewy bodies (LBs). The mechanisms responsible for neuronal degeneration in PD are complex and remain to be fully elucidated.

Mutations of DJ-1 are linked to autosomal recessive early-onset PD [1]. Extensive studies showed that DJ-1 has neuroprotective functions in anti-oxidative stress, anti-inflammation, mitochondrial regulation [2]. Loss of

\footnotetext{
*Correspondence: chen_sd@medmail.com.cn

${ }^{\dagger}$ Equal contributors

'Department of Neurology, and Institute of Neurology, Ruijin Hospital Affiliated to Shanghai Jiao Tong University School of Medicine, Shanghai 200025, China

${ }^{3}$ Parkinson's Disease Center, Beijing Institute for Brain Disorders, Beijing

100069, China

Full list of author information is available at the end of the article
}

DJ-1 function was shown to cause autosomal recessive PD [1]. In sporadic PD patients, the level of total DJ-1 protein was significantly reduced in the substantia nigra (SN) and CSF [3-5], although there were conflicting results [6]. These results suggested that lower DJ-1 level in PD patients may contribute to the pathogenesis of PD. However, the molecular mechanisms underlying the decreased DJ-1 level are not yet clear.

In recent years, epigenetic mechanisms such as DNA methylation, histone modification, chromatin remodeling and non-coding RNA regulation have been evidenced to play a role in regulating gene expression in neurodegenerative diseases [7-9]. DNA methylation at the 5-carbon position of cytosine residues located in dinucleotide CpG sites has the specific effect of reducing gene expression and unmethylated $\mathrm{CpG}$ sites are mostly linked to gene activation [10]. Reduced $\mathrm{CpG}$ island methylation in intron 1 of SNCA has been evidenced in 
PD brain tissue [11, 12], and hypomethylation of CpG was associated with increased a-synuclein expression [12]. Our previous results showed that the hypomethylation of SNCA in PD can also be detected in the bloodbased DNA methylation [13]. Eliezer Masliah et al. identified concordant methylation alterations in brain and blood by investigating genome-wide DNA methylation in brain and blood samples from PD patients and NC [14]. These reports from both of Eliezer Masliah et al. and us indicated that DNA extracted from leukocytes in peripheral blood might be a potential effective noninvasive source for screening epigenetic biomarker for PD diagnosis. Until now, no data on the methylation status of DJ-1 has been reported. In our study, we aimed to detect whether there was differential DNA methylation of DJ-1 in the peripheral blood between PD and NC groups and determine whether DNA methylation of DJ-1 in peripheral blood could represent the reduced expression of DJ-1 in PD patients. In SH-SY5Y cell model we tested whether DNA methylation can regulate DJ-1 expression by using methylation inhibitor.

\section{Methods}

\section{Subjects}

Forty PD patients, diagnosed by the UK PD brain bank criteria, were enrolled from the Department of Neurology, Ruijin Hospital affiliated to Shanghai Jiao Tong University School of Medicine, Shanghai, China; 40 NC were recruited from our previous epidemiological studies. For each subject, $5 \mathrm{ml}$ of blood samples and clinical data, such as name, gender, age, age of onset, duration, disease stage (H-Y stage) were collected. The PD and NC groups were well matched for age (PD: $63.7 \pm 6.16$ years; NC: $61.28 \pm 9.21$ years, $p=0.228)$ and gender (PD: 24/16; NC: 24/16). All the subjects have signed the informed consent form, and the study was approved by the Ruijin Hospital Ethics Committee, Shanghai Jiao Tong University School of Medicine.

\section{DNA extraction and bisulfite specific PCR-based sequencing method}

Genomic DNA was extracted from peripheral blood according to the standard procedures. CPGPLOT (http://emboss.bioinformatics.nl/cgi-bin/emboss/cpgplot) was used to identify and plot CpG islands in DJ-1 promoter region. Primer3 (http://frodo.wi.mit.edu/) was used to design PCR bisulfite conversion-specific primers (Table 1).

Bisulfite Specific PCR-based sequencing method was described in our previous report [13]. $1 \mu \mathrm{g}$ DNA was treated with EZ DNA Methylation-GoldKit (ZYMO RESEARCH) following the manufacture's protocol. After bisulfite conversion, unmethylated cytosines were converted to uracils, the converted product was purified followed by PCR amplification and sequencing. A $20 \mu \mathrm{l}$ mixture was prepared for each reaction and included $1 \times$ HotStarTaq buffer, $2.0 \mathrm{mM} \mathrm{Mg} 2+, 0.2 \mathrm{mM}$ dNTP, $0.2 \mu \mathrm{M}$ of each primer, $1 \mathrm{U}$ HotStarTaq polymerase (Qiagen Inc.) and $1 \mu \mathrm{l}$ template DNA. The cycling program was $95{ }^{\circ} \mathrm{C}$ for 15 mins; 11 cycles of $94{ }^{\circ} \mathrm{C}$ for 20 s, $60-0.5{ }^{\circ} \mathrm{C}$ per cycle for $40 \mathrm{~s}, 72{ }^{\circ} \mathrm{C}$ for $1 \mathrm{~min} ; 24$ cycles of $94{ }^{\circ} \mathrm{C}$ for $20 \mathrm{~s}, 54{ }^{\circ} \mathrm{C}$ for $30 \mathrm{~s}, 72{ }^{\circ} \mathrm{C}$ for $1 \mathrm{~min} ; 72{ }^{\circ} \mathrm{C}$ for 2 mins. 1U SAP and $6 \mathrm{U}$ Exo I were added into $8 \mu \mathrm{l}$ PCR products for PCR purification. The mixtures were incubated at $37^{\circ} \mathrm{C}$ for $60 \mathrm{mins}$, followed by incubation at $70{ }^{\circ} \mathrm{C}$ for $10 \mathrm{mins}$. In PCR amplification, the uracils were amplified as thymines, whereas $5-\mathrm{MeC}$ residues were amplified as cytosines. The PCR products were purified to remove any primer dimers and sequenced on an ABI $3730 \mathrm{XL}$ analyzer (Applied Biosystems and Life Technologies, USA). DNA methylation in the PCR target region was then read by scoring the remaining cytosine residues in the sequence. The degree of methylation at each $\mathrm{CpG}$ site from the direct sequencing profile was estimated by measuring the relative peak height of the cytosine $(\mathrm{C})$ versus cytosine plus thymine $(\mathrm{T})$ profile $(\mathrm{C} /(\mathrm{C}+\mathrm{T}) \%)$. As this can only be regarded as semi-quantitative, the degree

Table 1 Primers for PCR assays

\begin{tabular}{llll}
\hline Primer & Sequence $\left(5^{\prime}>3^{\prime}\right)$ & Tm $\left({ }^{\circ} \mathrm{C}\right)$ & Amplicon $(\mathrm{bp})$ \\
\hline DJ-1- CpG1-methylation-PCR-F & GTTYGGGAGGTTGGATTAGAGTT & 56 & 170 \\
DJ-1- CpG1-methylation-PCR-R & ACRACTCRATCCCACATAATACCC & \\
DJ-1- CpG2-methylation-PCR-F & TTGYGTAGTGTGGGGTTGAGG & 58 \\
DJ-1- CpG2-methylation-PCR-R & ACCRTCCAACACAAAAACACC & 141 \\
DJ-1- CpG1-methylation-Seq-R & ACRACTCRATCCCACATAATACCC & \\
DJ-1- CpG2-methylation-Seq-R & ACCRTCCAACACAAAAACACC & \\
DJ-1- Realtime-F & CGGGGTGCAGGCTTGTAAA & 58 \\
DJ-1- Realtime-R & TCCGGTTTCCTGCTCCTTC & 150 \\
\hline
\end{tabular}


Table 2 Clinical characteristics of subjects

\begin{tabular}{llll}
\hline & NC $(n=40)$ & PD $(n=40)$ & $P$-Value \\
\hline $\begin{array}{l}\text { Age, years } \\
\text { mean } \pm \text { sd(lowest,highest) }\end{array}$ & $61.28 \pm 9.21(59,80)$ & $63.7 \pm 6.16(45,83)$ & \\
$\begin{array}{l}\text { Gender } \\
\text { (male/female) }\end{array}$ & $24 / 16$ & $24 / 16$ \\
H\&Y stage & & \\
$\quad 1-2$ & - & 28 \\
$\quad 3$ & - & 8 & 1.0 \\
$4-5$ & - & 4 & - \\
& - & $5 \pm 2.7(2,14)$ & - \\
Duration, years & & & - \\
\hline
\end{tabular}

of methylation was expressed as $0,25,50,75$ or $100 \%$.

\section{Cell culture and treatment with 5-Aza-dC}

SH-SY5Y cells (ATCC) were cultured in DMEM with $10 \% \mathrm{FBS}, 100 \mathrm{U} / \mathrm{ml}$ penicillin/streptomycin (Invitrogen) and maintained at $37{ }^{\circ} \mathrm{C}$ with $5 \% \mathrm{CO}$. SH-SY5Y cells were chemically treated with 5 -Aza-dC (2.5 or $5 \mathrm{mM}$; Sigma). Real time PCR and Western blot were used to detect the mRNA and protein level of DJ-1. Total RNA was extracted from SH-SY5Y cells after $24 \mathrm{~h}$ 5-Aza-dC treatment by a standard method with TRIZOL Reagent (Invitrogen), and reverse-transcribed by using the PrimeScript $^{\oplus}$ RT reagent Kit (Takara) according to the manufacture's instruction. The mRNA levels were detected through real-time PCR by a standard method with Realtime PCR Master Mix (SYBR Green) kit (Takara). The primers for real-time PCR have been summarized in Table 1. We extracted the total protein of SH-SY5Y cells after 5-Aza-dC $48 \mathrm{~h}$ treatment. Rabbit anti-DJ-1 antibody (1:1000, sigma) were used for immunoblotting. The results were analyzed in three independent experiments.

\section{Statistical analysis}

Statistical analysis was performed using SPSS13.0 and $P<0.05$ was considered as significant. Statistical analysis included $t$ tests for age. One-way ANOVA was used to evaluate the differences in mRNA and protein levels among SH-SY5Y cells treated by AZA, DMSO and mock groups.

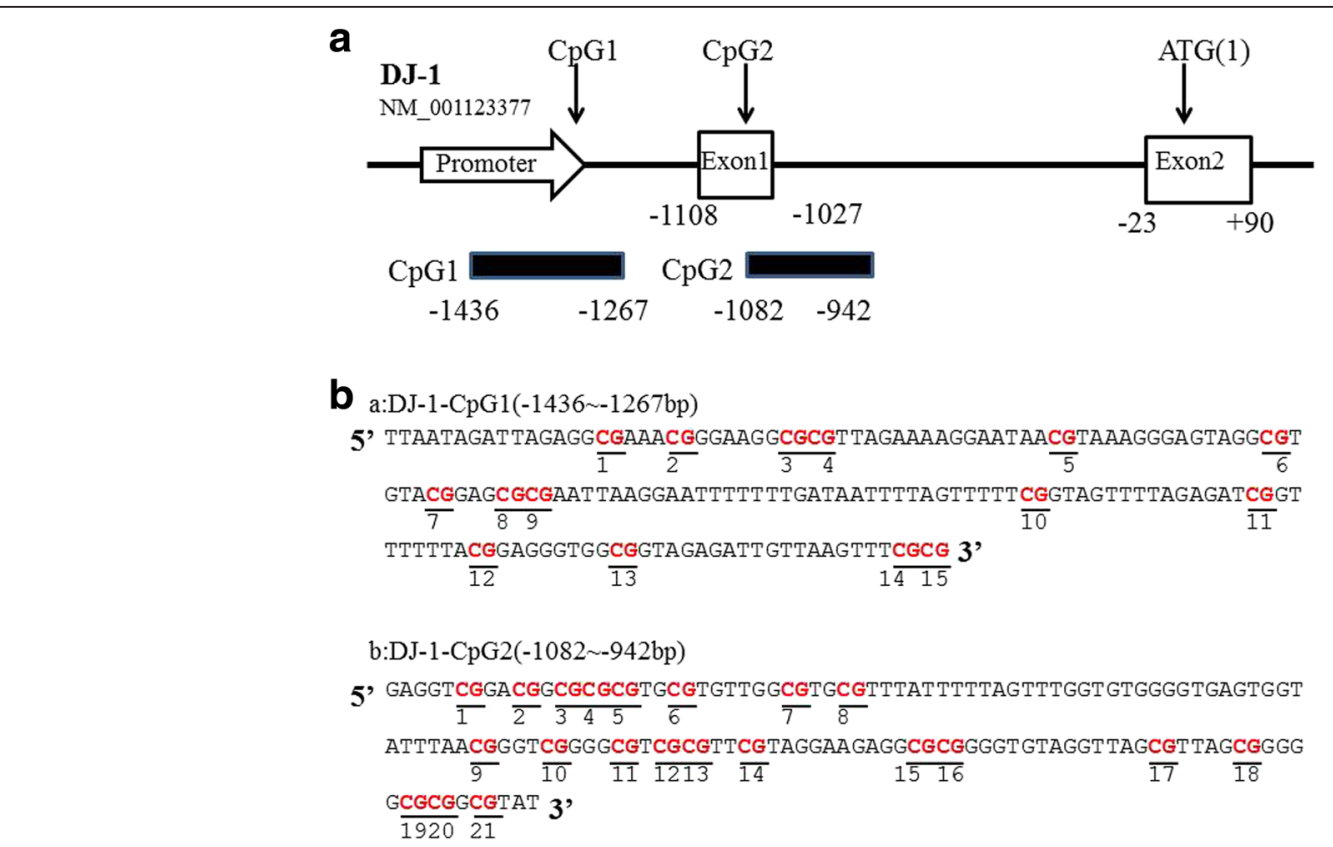

Fig 1 The two CpG islands in DJ-1. a Location of two CpG islands in DJ-1 (NM_001123377). b Sequence of CpG-1 islands in the promoter region of DJ-1 (a), sequence of CpG-2 islands in exon 1 of DJ-1(b) 
a Methylation of CpG sites 1-5 in CpG1 island

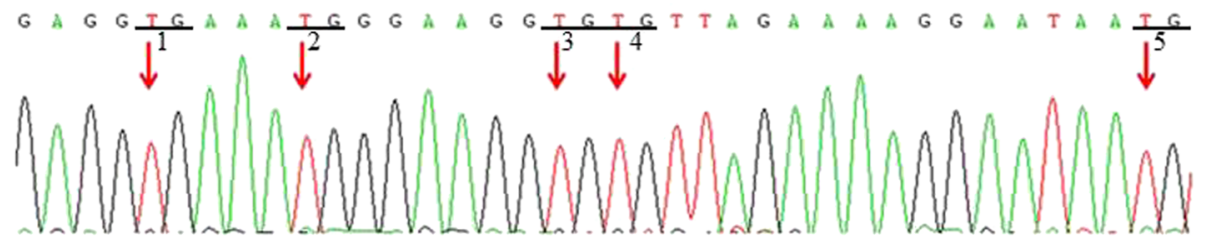

b Methylation of CpG sites $9-16$ in CpG2 island

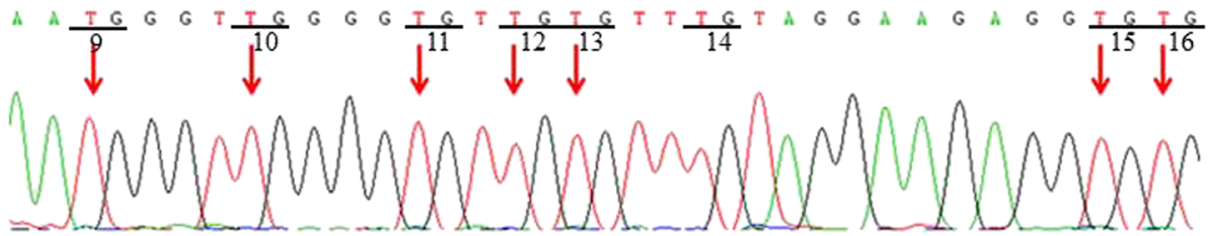

C Methylation of CpG1 island in 5 PD and 5 NC cases

d Methylation of CpG2 island in 5 PD and 5 NC cases

\begin{tabular}{|c|c|c|c|c|c|c|c|c|c|c|c|c|c|c|c|}
\hline \begin{tabular}{|c|c|c|c|c|c|}
\hline Co. \\
Cases
\end{tabular} & 1 & 2 & 3 & 4 & 5 & 6 & 7 & 8 & 0 & 10 & 11 & 12 & 13 & 14 & 15 \\
\hline PD1 & 0 & 0 & 0 & 0 & 0 & 0 & 0 & 0 & 0 & 0 & 0 & 0 & 0 & 0 & 0 \\
\hline PD2 & 0 & 0 & 0 & 0 & 0 & 0 & 0 & 0 & 0 & 0 & 0 & 0 & 0 & 0 & 0 \\
\hline PD3 & 0 & 0 & 0 & 0 & 0 & 0 & 0 & 0 & 0 & 0 & 0 & 0 & 0 & 0 & 0 \\
\hline PD4 & 0 & 0 & 0 & 0 & 0 & 0 & 0 & 0 & 0 & 0 & 0 & 0 & 0 & 0 & 0 \\
\hline PD5 & 0 & 0 & 0 & 0 & 0 & 0 & 0 & 0 & 0 & 0 & 0 & 0 & 0 & 0 & 0 \\
\hline NC1 & 0 & 0 & 0 & 0 & 0 & 0 & 0 & 0 & 0 & 0 & 0 & 0 & 0 & 0 & 0 \\
\hline NC2 & 0 & 0 & 0 & 0 & 0 & 0 & 0 & 0 & 0 & 0 & 0 & 0 & 0 & 0 & 0 \\
\hline NC3 & 0 & 0 & 0 & 0 & 0 & 0 & 0 & 0 & 0 & 0 & 0 & 0 & 0 & 0 & 0 \\
\hline NC4 & 0 & 0 & 0 & 0 & 0 & 0 & 0 & 0 & 0 & 0 & 0 & 0 & 0 & 0 & 0 \\
\hline NC5 & 0 & 0 & 0 & 0 & 0 & 0 & 0 & 0 & 0 & 0 & 0 & 0 & 0 & 0 & 0 \\
\hline
\end{tabular}

\begin{tabular}{|c|c|c|c|c|c|c|c|c|c|c|c|c|c|c|c|c|c|c|c|c|c|}
\hline $\begin{array}{c}\text { Cases } \\
\text { Co. } \\
\text { Co. }\end{array}$ & & 2 & & 4 & & 6 & & 8 & & 10 & & 12 & & 14 & is & 16 & 17 & is & 19 & & 21 \\
\hline PD1 & & 0 & & 0 & & & & & & & & 0 & & 0 & & 0 & 0 & 0 & 0 & & 0 \\
\hline PD2 & & 0 & & 0 & & 0 & & 0 & & 0 & & 0 & & 0 & & 0 & 0 & 0 & 0 & & \\
\hline PD3 & & 0 & & 0 & & 0 & & & & O & & 0 & & 0 & 0 & 0 & 0 & 0 & 0 & & \\
\hline PD4 & & 0 & & 0 & & 0 & & 0 & & 0 & & 0 & & 0 & 0 & 0 & 0 & 0 & 0 & & \\
\hline PDS & & 0 & 0 & 0 & 0 & 0 & 0 & 0 & & 0 & & 0 & & 0 & 0 & 0 & 0 & 0 & 0 & & 0 \\
\hline $\mathrm{NC} 1$ & 0 & 0 & 0 & 0 & 0 & 0 & 0 & 0 & 0 & 0 & & 0 & & 0 & 0 & 0 & 0 & 0 & 0 & 0 & 0 \\
\hline $\mathrm{NC2}$ & & 0 & 0 & 0 & 0 & 0 & 0 & 0 & 0 & 0 & & 0 & & 0 & 0 & 0 & 0 & 0 & 0 & 0 & 0 \\
\hline $\mathrm{NC} 3$ & & 0 & 0 & 0 & 0 & 0 & 0 & 0 & 0 & 0 & 0 & 0 & & 0 & 0 & 0 & 0 & 0 & 0 & 0 & 0 \\
\hline $\mathrm{NC4}$ & & 0 & 0 & 0 & 0 & 0 & 0 & 0 & 0 & 0 & 0 & 0 & & 0 & 0 & 0 & 0 & 0 & 0 & 0 & 0 \\
\hline $\mathrm{NCS}$ & & 0 & & 0 & & 0 & & 0 & & 0 & 0 & 0 & & 0 & 0 & 0 & 0 & 0 & 0 & 0 & \\
\hline
\end{tabular}

Fig 2 Bisulfite specific PCR-based sequencing analysis of two CpG islands methylation in 40 PD patients and 40 normal controls. a and $\mathbf{b}$ Unmethylated cytosines (c) were converted to uracil $(U)$ after bisulfite treatment and amplified as thymines (T) in PCR amplication. Unmethylated CpG sites 1-5 in CpG1 island and CpG sites 9-16 in CpG2 island were shown here as an example. c and $\mathbf{d}$ All the CpG sites of these two CpG islands were unmethylated. Here are the methylation of $\mathrm{CpG} 1$ island and $\mathrm{CpG} 2$ island from 5 PD and 5 NC cases, and the rest cases showed the exact same methylation pattern

\section{Results}

1. Demographic characteristics

The clinical characteristics are listed in Table 2. Each group comprised 24 men and 16 women, and there was no significant difference in age $(P=0.228)$ between the PD patients $(63.7 \pm$ 6.16 years) and NC (61.28 \pm 9.21 years). Among the PD patients, 28 had mild degree of the disease ( $\mathrm{H} \& \mathrm{Y}$ stage $1-2$ ), 8 moderate (H\& Y stage 3 ), and 4 severe (H\&Y stage 4-5). Disease duration of 40 PD patients was $5 \pm 2.7$ years.

2. DNA Methylation of DJ-1 promoter region detected by Bisulfite specific PCR-based sequencing method Based on the NCBI database, the promoter region of human DJ-1 gene (NM_001123377) has two CpG islands (CGIs), locating at-1545 $-1244 \mathrm{bp}(\mathrm{CpG} 1),-1178 \sim-732 \mathrm{bp}(\mathrm{CpG} 2)$ upstream of the translation initiation site

(Fig. 1a). CpG1 has 15 CpG sequences (Fig. 1b, a). CpG2 contains 21 CpG sequences (Fig. 1b, b). Bisulfite specific PCR-based sequencing method was used to examine the average methylation level at each CpG site (See methods). Our results showed that all the CpG sites probed in the two CGIs were unmethylated in both PD and NC (Fig. 2). The stable unmethylated status of $\mathrm{CpG}$ sites in both PD and NC group indicated that CpG methylation in the promoter region of DJ-1 in PBLs might have very limited or no regulatory effects on DJ-1 expression.

3. No effects of methylation inhibitor on the DJ-1 expression in SH-SY5Y cell model

Previous whole genome bisulfite sequencing (WGBS) study showed that DNA methylation can be detected in various regions, including CGIs, gene 


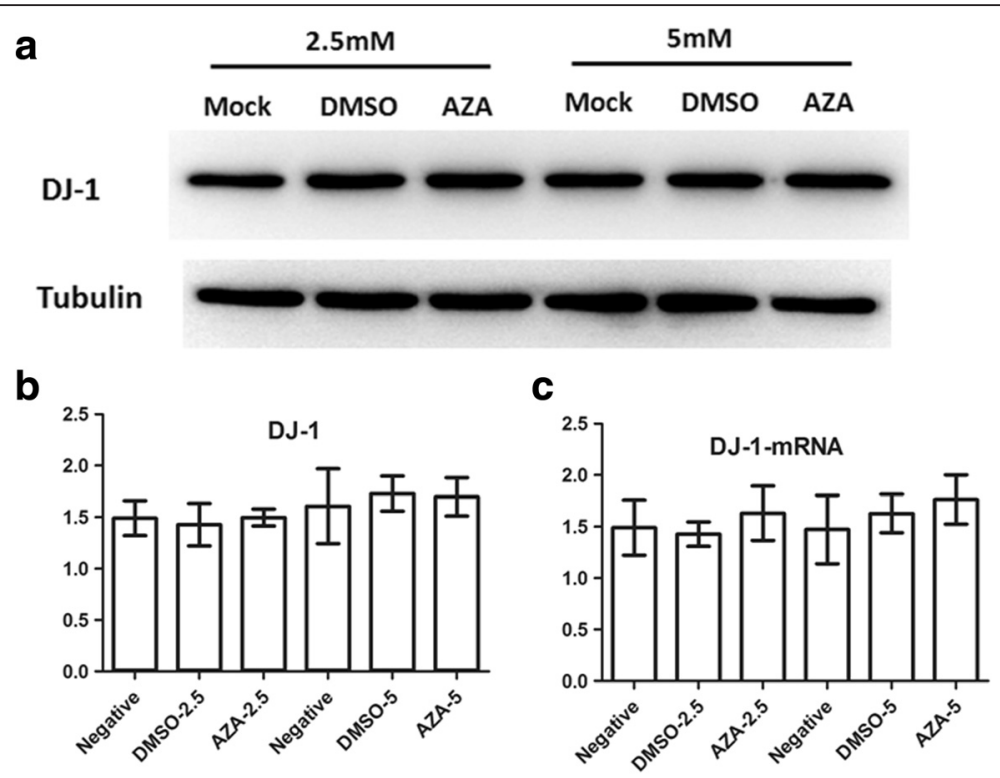

Fig 3 The mRNA and protein levels of DJ-1 did not change in 5-Aza-dC treated SH-SY5Y cells. Western blot and RT-PCR showed no significant change of DJ-1 protein level ( $\mathbf{a} \& \mathbf{b})$ and mRNA level $(\mathbf{c})$ among 5-Aza-dC treated, DMSO treated and mock cells. Bar plot indicated the statistical analysis of DJ-1 protein level (b) and mRNA level (c) (Mean \pm SD, ${ }^{*} p<0.05$ )

bodies and tandem repeating-containing regions [15]. Moreover, methylation levels in these regions can regulate the transcription levels $[15,16]$. Although the CpG sites probed in this study were unmethylated in both PD and NC group, the other $\mathrm{CpG}$ sites out of the promoter region haven't been determined. In order to test whether CpG methylation level can regulate the DJ-1 expression, methylation inhibitor 5-Aza-dC was used to demethylate the CpG sites in a SH-SY5Y cell model, then DJ-1 expression was detected in the mRNA and protein level. Our results showed DJ-1 expression didn't have significant change in both the mRNA and protein level in SH-SY5Y cells treated with $2.5 \mathrm{mM}$ or $5 \mathrm{mM} 5$-Aza-dC compared with the untreated cells (Fig. 3). Thus, the results indicated that DNA methylation had no regulatory effects on DJ-1 expression in SH-SY5Y cell model.

\section{Discussion}

PD can begin years before the appearance of clinical motor symptoms when a significant number of nigrostriatal dopaminergic neurons have already been degenerated. The detection of PD prior to the emergence of motor symptoms is important for early diagnosis, neuroprotective treatment, monitoring disease progression and response to therapy. Thus, reliable biomarkers, which can represent a pathological process and can be easily detected, are needed. DJ-1 detected from brain [3], CSF [4, 5] and saliva [17] has been thought as a candidate biomarker of PD [18]. Recently, blood-based DNA methylation represents a highly promising biomarker for PD $[13,14]$ by regulating the causative gene expression. Thus, in the present study, we explored whether there was different DNA methylation level of DJ-1 in the PBLs between PD patients and NC.

Our results showed that in the two CGIs that we probed, all the $\mathrm{CpG}$ sites were unmethylated in both $\mathrm{PD}$ group and $\mathrm{NC}$ group, indicating that $\mathrm{CpG}$ methylation in the promoter region of DJ-1 in PBLs might have very limited or no regulatory effects on DJ-1 expression and could not be used as a biomarker to reflect DJ-1 expression changes in brains of PD patients and NC. However, previous WGBS study showed that DNA methylation can be detected in various regions, including CGIs, gene bodies and tandem repeating-containing regions [15]. Methylation levels in these regions can also regulate the transcription levels $[15,16]$. Bisulfite specific PCR-based sequencing method used in our study only favored those CpG sites contained within CGIs and promoter regions [16]. Thus all other CpG sites out of the CGIs and promoter region can't be probed by this method. In order to confirm whether CpG methylation can regulate the DJ-1 expression, we used methylation inhibitor to treat $\mathrm{SH}$ SY5Y cells, then DJ-1 expression was detected in the mRNA and protein level. Our results revealed that there was no significant expression change of DJ-1 between the cells treated with methylation inhibitor and non-treated cells. Thus, our results indicated that DNA methylation might not be the key factor in regulating DJ-1 expression. 
Generally, gene expression can be regulated in three different levels, transcriptional, mature mRNA processing and translational level. In the transcriptional level, both Sp1 and $\mathrm{X}$-box-binding protein-1S (XBP-1S) were identified as transcription regulatory factor interacting with the DJ-1 promoter, thereby enhancing its promoter trans-activation, mRNA levels and protein expression $[19,20]$. In mRNA processing level, miR-494 was found to decrease DJ-1 expression by binding to the 3'UTR of DJ-1 [21]. Till now, the epigenetic mechanism in modulating DJ-1 expression has not been fully explored. Zhou W et al. reported that phenylbutyrate, a HDAC inhibitor, can up-regulate the DJ-1 protein, indicating that DJ-1 expression can be regulated by histone modification [22]. In our study, we explored the possibility that whether DJ1 expression can be regulated by the DNA methylation. We did not find differential CpG sites methylation in the CGIs of DJ-1 promoter region between PD and NC group, and there was no significant change of DJ-1 expression in a SH-SY5Y cell model treated by methylation inhibitor.

However, there were some limitations in our study. First, the sample size is small, and brain tissue as a standard control is not available in our country. Second, bisulfite specific PCR-based sequencing method used in our study is a convenient and economic method for DNA methylation screening, but it is a semi-quantitative method and only favored those CpG sites in the CGIs and promoter region [16]. Usually, we use PCR-based sequencing method for screening, if it provides any clue of different methylation, we would use bisulfite specific cloning-based sequencing, which is a more accurate and sensitive method to test the cytosine methylation at each CpG site in individual molecules [23], for further study. In this study, no methylated CpG sites were found in both PD and NC. Thus, the results would be the same even bisulfite specific cloning-based sequencing was used. As bisulfite specific PCR-based method only favors those CpG sites in CGIs and promoter region, in order to detect any regulatory effect of $\mathrm{CpG}$ sites methylation out of CGIs and promotor region on DJ-1 expression, we treated SH-SY5Y cells with methylation inhibitor and tested the DJ1 expression level from both the mRNA and protein level, and our results confirmed no regulatory effects of DNA methylation on DJ-1 expression. In this study, we tried our best to get the truth, but the objective limits still exist. For further study, WGBS would be a good way to obtain an unbiased and more complete representation of the methylome by testing in both human brain tissue and PBLs.

\section{Conclusions}

CpG sites are unmethylated in DJ-1 promoter region of PBLs from both PD patients and NC. DNA methylation inhibitor didn't alter DJ-1 gene expression in SH-SY5Y cell model. Our results indicated that methylation status of DJ1 had no obvious regulatory effects on DJ-1 expression, and might not be an efficient biomarker for PD patients.
Competing interests

We declare we have no competing interests.

\section{Authors' contributions}

Chen SD, Ding JQ, Tan YY participated in the design of the study; Wu L, Li $\mathrm{DH}$, Liu XL performed the research; Wu $L$ performed the statistical analysis. Tan YY prepared the manuscript. Chen SD revised the manuscript. All authors read and approved the final manuscript.

\section{Acknowledgments}

This work was supported by the National Program of Basic Research (2011CB504104) of China, Natural Science Fund (81430022, 81371407, 30872729, 30971031), The Twelfth Five-year National Science and Technology Support Program (2012BAl10B03), Shanghai Key Project of Basic Science Research (10411954500). We acknowledge all the patients and healthy subjects for their generous donations of blood samples without which this study could not be carried out.

\section{Author details}

${ }^{1}$ Department of Neurology, and Institute of Neurology, Ruijin Hospital Affiliated to Shanghai Jiao Tong University School of Medicine, Shanghai 200025, China. ${ }^{2}$ Department of Neurology, Shanghai Ninth People's Hospital Affiliated to Shanghai Jiao Tong University School of Medicine, Shanghai 200011, China. ${ }^{3}$ Parkinson's Disease Center, Beijing Institute for Brain Disorders, Beijing 100069, China.

Received: 26 November 2015 Accepted: 11 February 2016 Published: 31 March 2016

\section{References}

1. Bonifati V, Rizzu P, van Baren MJ, Schaap O, Breedveld GJ, Krieger E, Dekker MC, Squitieri F, Ibanez $P$, Joosse $M$, van Dongen JW, Vanacore $N$, van Swieten JC, Brice A, Meco G, van Duijn CM, Oostra BA, Heutink P. Mutations in the DJ-1 gene associated with autosomal recessive early-onset parkinsonism. Science. 2003;299(5604):256-9.

2. Ariga $H$, Takahashi-Niki K, Kato I, Maita H, Niki T, Iquchi-Ariga SM. Neuroprotective function of DJ-1 in Parkinson's disease. Oxid Med Cell Longev. 2013;2013:683920.

3. Nural H, He P, Beach T, Sue L, Xia W, Shen Y. Dissembled DJ-1 high molecular weight complex in cortex mitochondria from Parkinson's disease patients. Mol Neurodegener. 2009;4:23.

4. Hong Z, Shi M, Chung KA, Quinn JF, Peskind ER, Galasko D, Jankovic J, Zabetian CP, Leverenz JB, Baird G, Montine TJ, Hancock AM, Hwang H, Pan C,Bradner J, Kang UJ, Jensen PH, Zhang J. DJ-1 and alpha-synuclein in human cerebrospinal fluid as biomarkers of Parkinson's disease. Brain. 2010; 133(Pt 3):713-26.

5. Shi M, Bradner J, Hancock AM, Chung KA, Quinn JF, Peskind ER, Galasko D, Jankovic J, Zabetian CP, Kim HM, Leverenz JB, Montine TJ, Ginghina C, Kang UJ, Cain KC, Wang Y, Aasly J, Goldstein D, Zhang J. Cerebrospinal fluid biomarkers for Parkinson disease diagnosis and progression. Ann Neurol. 2011:69(3):570-80.

6. Waragai M, Wei J, Fujita M, Nakai M, Ho GJ, Masliah E, Akatsu H, Yamada T, Hashimoto M. Increased level of DJ-1 in the cerebrospinal fluids of sporadic Parkinson's disease. Biochem Biophys Res Commun. 2006;345(3):967-72.

7. Qureshi IA, Mehler MF. Advances in epigenetics and epigenomics for neurodegenerative diseases. Curr Neurol Neurosci Rep. 2011;11(5):464-73.

8. Marques SC, Oliveira CR, Pereira CM, Outeiro TF. Epigenetics in neurodegeneration: a new layer of complexity. Prog Neuropsychopharmacol Biol Psychiatry. 2011;35(2):348-55.

9. Migliore L, Coppedè F. Genetics environmental factors and the emerging role of epigenetics in neurodegenerative diseases. Mutat Res. 2009;667(1-2): 82-97.

10. Jiricny J, Menigatti M. DNA cytosine demethylation: are we getting close? Cell. 2008;135:1167e9.

11. Jowaed A, Schmitt I, Kaut O, Wullner U. Methylation regulates alphasynuclein expression and is decreased in Parkinson's disease patients' brains. J Neurosci. 2010;30:6355e9.

12. Matsumoto L, Takuma H, Tamaoka A, Kurisaki H, Date H, Tsuji S, Iwata A. CpG demethylation enhances alpha-synuclein expression and affects the pathogenesis of Parkinson's disease. PLoS One. 2010;5(11), e15522. 
13. Tan YY, Wu L, Zhao ZB, Wang Y, Xiao Q, Liu J, Wang G, Ma JF, Chen SD. Methylation of a-synuclein and leucine-rich repeat kinase 2 in leukocyte DNA of Parkinson's disease patients. Parkinsonism Relat Disord. 2014;20(3): 308-13.

14. Masliah E, Dumaop W, Galasko D. Desplats. PD distinctive patterns of DNA methylation associated with Parkinson disease: identification of concordant epigenetic changes in brain and peripheral blood leukocytes. Epigenetics. 2013;8(10):1030-8.

15. Okae H, Chiba H, Hiura H, Hamada H, Sato A, Utsunomiya T, Kikuchi H, Yoshida H, Tanaka A, Suyama M, Arima T. Genome-wide analysis of DNA methylation dynamics during early human development. PLoS Genet. 2014; 10(12), e1004868.

16. Kobayashi H, Sakurai T, Imai M, Takahashi N, Fukuda A, Yayoi O, Sato S, Nakabayashi K, Hata K, Sotomaru Y, Suzuki Y, Kono T. Contribution of intragenic DNA methylation in mouse gametic DNA methylomes to establish oocyte-specific heritable marks. PLoS Genet. 2012;8(1), e1002440.

17. Kang WY, Yang $Q$, Jiang $X F$, Chen $W$, Zhang $L Y$, Wang $X Y$, Zhang $L N$, Quinn TJ, Liu J, Chen SD. Salivary DJ-1 could be an indicator of Parkinson's disease progression. Front Aging Neurosci. 2014;6:102.

18. Haas BR, Stewart TH, Zhang J. Premotor biomarkers for Parkinson's disease a promising direction of research. Transl Neurodegener. 2012;1(1):11.

19. Taira T, Takahashi K, Kitagawa R, Iguchi-Ariga SM, Ariga H. Molecular cloning of human and mouse DJ-1 genes and identification of Sp1-dependent activation of the human DJ-1 promoter. Gene. 2001;263(1-2):285-92.

20. Duplan E, Giaime E, Viotti J, Sévalle J, Corti O, Brice A, Ariga H, Qi L, Checler $F$, Alves da Costa C. ER-stress-associated functional link between Parkin and DJ-1 via a transcriptional cascade involving the tumor suppressor p53 and the spliced X-box binding protein XBP-1. J Cell Sci. 2013;126(9):2124-33.

21. Xiong R, Wang Z, Zhao Z, Li H, Chen W, Zhang B, Wang L, Wu L, Li W, Ding J, Chen S. MicroRNA-494 reduces DJ-1 expression and exacerbates neurodegeneration. Neurobiol Aging. 2014;35(3):705-14.

22. Zhou W, Bercury K, Cummiskey J, Luong N, Lebin J, Freed CR. Phenylbutyrate up-regulates the DJ-1 protein and protects neurons in cell culture and in animal models of Parkinson disease. J Biol Chem. 2011; 286(17):14941-51.

23. Clark SJ, Statham A, Stirzaker C, Molloy PL, Frommer M. DNA methylation: bisulphite modification and analysis. Nat Protoc. 2006;1 (5):2353e64.

\section{Submit your next manuscript to BioMed Central and we will help you at every step:}

- We accept pre-submission inquiries

- Our selector tool helps you to find the most relevant journal

- We provide round the clock customer support

- Convenient online submission

- Thorough peer review

- Inclusion in PubMed and all major indexing services

- Maximum visibility for your research

Submit your manuscript at www.biomedcentral.com/submit 